This is the post print version of the article, which has been published in Acta Oto-laryngologica. 2018,

\title{
Long-term results of atresiaplasty in patients with congenital aural atresia
}

\author{
Juuso Pellinen BM1ㄱ Juha-Pekka Vasama MD PhD², Ilkka Kivekäs MD PhD,2 \\ ${ }^{1}$ Department of Otorhinolaryngology, Tampere University Hospital, and School of Medicine, \\ University of Tampere, Tampere, Finland \\ ${ }^{2}$ Department of Otorhinolaryngology, Tampere University Hospital, Tampere, Finland
}

Conflict of Interest: The authors declare that they have no conflict of interest.

The word count of the manuscript: 2008

Address correspondence and reprint requests to: Dr Ilkka Kivekäs, Department of Ear and Oral Diseases, Tampere University Hospital, P.O. Box 2000, FIN-33521 Tampere, Finland. Email: ilkka.kivekas@pshp.fi 


\begin{abstract}
Conclusion: Surgery for congenital aural atresia (CAA) is a demanding operation with variable anatomical and hearing outcomes. Atresiaplasty operations should be centralized to hospitals with large numbers of such patients to ensure sufficient levels of surgical experience. Bone-anchored hearing devices or middle-ear implants should be considered as a first line option because they offer good hearing predictability.

Objectives: To evaluate long-term benefits of atresiaplasty on hearing and the impact of surgery on quality of life in congenital aural atresia (CAA) patients.

Methods: We evaluated the long-term hearing results, impact of atresiaplasty on quality of life (QoL), the meatal diameter of operated ear canal, and the cumulative number of post-operative hospital visits in 14 CAA patients, on average, 12 years (range 4-17 years) post operatively. Results: The mean preoperative pure tone average (PTA) was $61 \mathrm{~dB}$ HL. The postoperative short-term PTA was $36 \mathrm{~dB}$ HL and the long-term PTA was $51 \mathrm{~dB}$ HL. The mean total Glasgow Benefit Inventory (GBI) score was 16 (range -11-39), showing the positive benefit of atresiaplasty on QoL. The mean postoperative diameter of the auditory meatus was $6 \mathrm{~mm}$. The average number of hospital outpatient visits during the first postoperative year was 10 .
\end{abstract}

\title{
Introduction
}

Congenital aural atresia (CAA) comprises a variety of external auditory canal and middle ear malformations. In severe cases, the ear canal cannot be detected at all or it may end in a short blind pouch, and the ossicles may be absent or anomalous in the middle ear. In milder cases, the ear canal is narrower to a variable degree. CAA is often associated with microtia or incomplete development of the auricle, and it may cause severe conductive hearing loss [1,2]. The incidence of CAA is 18/20,000 live births, and unilateral cases are 3-7 times more common than bilateral cases [3,4].

Patients with unilateral CAA may experience difficulties in speech discrimination and determining the direction of sound. However, most of these patients do not want or need any hearing rehabilitation. The surgical options for hearing rehabilitation are bone-anchored hearing devices, middle ear implants, and atresiaplasty. 
Reconstruction of the external ear canal, tympanic membrane, and functional middle ear system is one of the most challenging otological operations due to the increased risk of facial nerve damage and minor postoperative complications. Narrowing of the reconstructed external ear canal, development of recalcitrant granulation tissue, and lateralization of the tympanic membrane are some of the common causes leading to poor results after atresiaplasty [5-8].

In this study, we assess the long-term postoperative outcome (hearing results, surgical success rate, and quality of life) of atresiaplasty in patients with CAA.

\section{Materials and Methods}

The study design was approved by the ethical review board of Pirkanmaa hospital district (Tampere University Hospital, Tampere, Finland), and informed consent was obtained from all participants. Using the codes 7440X (ICD9) and Q16.1 (ICD10) as search criteria, a total of 125 CAA patients were found. Twenty-two out of 125 patients had had atresiaplasty, and they were invited to participate in the study. Fourteen of the 22 patients (15 ears, 9 males/5 females, mean age 22 years, range 8-53 years) with 13 unilateral and one with bilateral CAA replied and were included. The average follow-up time was 12 years (range 4-17 years). All operations had been performed at Tampere University Hospital between 1997 and 2011 by two experienced, senior otologic surgeons.

The patients' medical records showed that preoperatively eight ears had total atresia, four ears had partial atresia, and three ears had a stenotic ear canal based on Altmann's classification [9]. In this classification, total atresia is defined as the absence of the entire ear canal. In partial atresia, the ear canal ends in a bony barrier, and in a stenotic ear, the ear canal is narrow and the tympanic membrane is small in most cases. In addition, 10 patients had microtia, and one patient had mild congenital facial nerve weakness. Preoperative high-resolution computed tomography (HRCT) revealed exceptionally small or deformed ossicles in 8 out of 15 ears. No inner ear or cochlear nerve malformations were detected.

All operated ears were examined and the patients' quality of life (QoL) was evaluated. The status of the reconstructed ear canal was documented and its diameter was measured from the opening of the bony ear canal using an ear funnel as a gauge. The QoL was measured using the Glasgow Benefit Inventory (GBI) [10]. The GBI scores depict the positive or negative impact of the atresiaplasty on 
the patient's QoL. The test contains 18 questions and the response to each question is placed on a five-point scale ranging from a large deterioration to a large improvement in health status. The GBI consists of a total score and three subscores (general, social support, and physical health). The total score is transposed onto a benefit scale ranging from -100 (maximal negative benefit), through 0 (no benefit), to +100 (maximal positive benefit). Hearing was measured in a soundproof booth using pure tones, and the pure-tone average (PTA, the mean of $0.5,1,2$, and $4 \mathrm{kHz}$ ) was calculated. The short-term (2-17-month) postoperative PTA was gathered from the patients' records.

\section{Results}

The mean preoperative PTA was $61 \mathrm{~dB}$ HL (range 31-83 dB HL) and the mean air-bone gap (ABG) was $51 \mathrm{~dB}$ HL (range 31-64 dB HL). The preoperative PTA was $56 \mathrm{~dB}$ HL in stenotic ears, $57 \mathrm{~dB}$ $\mathrm{HL}$ in ears with partial atresia, and $65 \mathrm{~dB}$ HL in ears with total atresia. The ABGs were $49 \mathrm{~dB}$ HL, $46 \mathrm{~dB}$ HL, and $56 \mathrm{~dB}$ HL, respectively.

The mean short-term postoperative PTA was $49 \mathrm{~dB}$ HL in patients with stenotic ears, $36 \mathrm{~dB}$ HL in patients with partial atresia, and $32 \mathrm{~dB}$ HL in patients with total atresia, while the mean short-term postoperative ABGs were $33 \mathrm{~dB} H \mathrm{HL}, 28 \mathrm{~dB} \mathrm{HL}$, and $28 \mathrm{~dB} \mathrm{HL}$, respectively. The corresponding mean long-term PTAs were $45 \mathrm{~dB}$ HL, $48 \mathrm{~dB}$ HL, and $54 \mathrm{~dB}$ HL, respectively, while the mean longterm postoperative ABGs were $32 \mathrm{~dB}$ HL, $26 \mathrm{~dB} \mathrm{HL}$, and $44 \mathrm{~dB} \mathrm{HL}$, respectively. In the long-term follow-up, less than $30 \mathrm{~dB}$ HL ABG was achieved in two stenotic ears, in three ears with partial atresia, and in no ears with total atresia. Ossicles were mobilized in 9 cases and in one case the deform ossicles were reconstructed by bone cement. In these cases the mean short-term PTA was $29 \mathrm{~dB}$ HL and the mean ABG was $24 \mathrm{~dB}$ HL and the mean long-term PTA was $45 \mathrm{~dB}$ HL and the mean ABG was $34 \mathrm{~dB}$ HL. In 5 cases ossicles were determined as mobile and no reconstruction were done. In this group the mean short-term PTA was $47 \mathrm{~dB}$ HL and the mean ABG was $40 \mathrm{~dB} \mathrm{HL}$ and corresponding the mean long-term PTA was $60 \mathrm{~dB}$ HL and the mean ABG was $41 \mathrm{~dB}$ HL. Tympanic membrane was created in 14/15 cases.

No major intraoperative complications were noted, including sensorineural hearing loss or facial nerve damage. In two cases the temporomandibular joint became exposed, but these didn't cause any harm to the patients in long-term follow-up. In long-term follow-up excessive adhesive re-stenosis was noted in 6/15 ears, where 5 out of 6 cases were in total atresia group. 
Postoperative hearing rehabilitation was recommended to six out of 14 patients. A bone-anchored hearing device was offered to five patients, but finally only one patient received a Cochlear ${ }^{\mathrm{TM}}$ BAHA $^{\circledR}$, while another patient received a MED EL ${ }^{\mathrm{TM}}$ Bonebridge ${ }^{\circledR}$. A hearing aid was fitted for one patient. For unknown reasons, hearing rehabilitation was not offered to six patients, although their mean PTA was $46 \mathrm{~dB}$ HL (range 34-75 dB HL). In two patients with a PTA less than $30 \mathrm{~dB}$ HL, hearing rehabilitation was not needed.

The mean postoperative diameter of the auditory canal was $6 \mathrm{~mm}$ (range $0-11 \mathrm{~mm}$ ). Better results were achieved in stenotic ears (mean $7.5 \mathrm{~mm}$ ) than in ears with partial (mean $5.5 \mathrm{~mm}$ ) or total atresia (mean $6.0 \mathrm{~mm}$ ). There wasn't any correlation between the follow-up time and the diameter of the ear canal.

The average number of hospital admissions during the first postoperative year was 10 (range 5-17) per patient. At the end of the follow-up, the cumulative number of visits was 21 (range 7-39). The number of control visits depends on the tendency for re-stenosis, granulation tissue overgrowth, and infections. Excessive adhesive re-stenosis led to revision surgeries in four of the 14 patients, all in ears with total atresia. In two cases cartilage part meatal stenosis lead to the revision surgery.

The mean total GBI score showed the positive benefit of atresiaplasty in 13 out of 14 patients, Figure 1. The GBI score increased as a function of the severity of the CAA and was 4 in patients with a stenotic ear, 18 in patients with partial atresia, and 21 in patients with total atresia.

\section{Discussion}

Previous studies have reported good long-term hearing results after CAA surgery. Chang et al. (2006) reviewed the results of 100 operated ears with a mean follow-up time of 57 months. Some $64 \%$ of their patients achieved an ABG of $30 \mathrm{~dB}$ HL or less, which is superior to our results (33\%) [7]. Even better long-term (over 12 months) hearing results were seen in Digoy's (2007) study, in which 10 out of 13 patients (74\%) had a postoperative ABG of $30 \mathrm{~dB}$ HL or less. Moreover, in 12 patients, the mean postoperative PTA was 18 dB HL better than preoperatively [6]. Edfeldt et al. (2015) reported that over $80 \%$ of their 100 atresia patients obtained an ABG less than $30 \mathrm{~dB}$ HL. Nadaraja et al (2013) performed a systematic review to compare the hearing results of atresia surgery and osseointegrated bone conduction device in CAA patients [11]. 11 of 35 atresiaplasty studies evalueted PTA less than 
$30 \mathrm{~dB}$ as a successful result and it was obtained in $60 \%$ of 390 ears. The mean short-term hearing gain in all atresiaplasty patients was $24 \mathrm{~dB}$, whereas osseointegrated bone conduction device shortterm hearing gain was $38 \mathrm{~dB}$. Deterioration of the hearing outcome in CAA patients within time was seen. In our study, only three patients (21\%) - those with a stenotic ear canal - had a postoperative PTA of $30 \mathrm{~dB}$ HL or less - i.e. a result that could be considered successful [12].

Our results suggest that less severe CAA associates with better long-term hearing results. Surprisingly, our short-term hearing results did not correlate with atresia severity. The mobilization of the ossicles either by laser or by diamond drill seems to lead better hearing results in short-term (mean PTA 29 vs $47 \mathrm{~dB}$ HL) and long-term follow-up (mean PTA 45 vs $60 \mathrm{~dB}$ HL). The slow postoperative tissue regrowth leading to meatal narrowing seems to be more likely in total atresia, which partly explains poorer long-term hearing results in these patients. In stenotic ear canals, the operation is smaller and the original canal skin can, in most cases, be left intact to prevent potential postoperative stenosis. Revision surgery was performed on four patients, but the surgery did not lead to improved hearing in any of the patients. The major problems with most of the ears in the long-term follow-up were narrowing of the medial ear canal and thick adhesion on the level of the tympanic membrane. The diameter of the bony ear canal normally varies 6-9 $\mathrm{mm}$. In our series, the mean diameter of the bony ear canal was close to normal, at $6.0 \mathrm{~mm}$.

The poor hearing results in our study may partly be explained by inexperience. Finland has a small population and therefore CAA operations are very rare. There are only 3-20 new CAA cases per year in the whole country. Between 1997 and 2011, an average of two atresiaplasties per year were performed at our hospital. Taking into account that not all CAA patients are candidates for surgical treatment because of anatomical or patient-related reasons, the centralization of all operations in Finland would still not lead to even one surgeon gaining sufficient experience to improve efficacy. Therefore, there is a case to be made for multinational cooperation to bring all Nordic CAA operations to one hospital with a specialization in this surgery. This would guarantee more operations for surgeons and theoretically lead to better results.

Many patients required numerous control visits during the first postoperative year, some even for a longer period. Revision operations were also performed. Despite the disappointing hearing results, all but one patient reported a positive impact of the surgery on QoL. However, relatively low positive scores in all GBI subgroups indicate that the surgery had only a minor impact on the QoL, regardless 
of the preoperative state. Despite the results, the majority of the patients reported that they would go through the surgical treatment again. None of the patients claimed that the surgery caused any harm.

The importance of binaural hearing is emphasized in noisy backgrounds and in determining the direction of sounds. Bone-anchored hearing devices and middle ear implants are an alternative to CAA surgery. Different kinds of devices transmitting the kinetic energy of the sound to the inner ear are available. Some devices require an external abutment through the skin to connect the bone-anchored device to the audioprocessor, but in the latest generation of the devices, this has been replaced by a transcutaneous magnet system. Despite potential skin problems [13-15] and aesthetic issues, the hearing results are predictable and in most cases stable over time. In conductive hearing loss, hearing results improve with bone-anchored hearing devices from 20 to $35 \mathrm{~dB}$ HL, with the results being better with percutaneous devices and worse with passive transcutaneous magnet devices [16-19]. In our study, despite the modest postoperative hearing results, only a few patients were offered other rehabilitation options. Bone-anchored hearing devices, middle ear implants, and hearing aids should be actively presented to all CAA patients with insufficient hearing results.

\section{Conclusion}

This study reports on the surgical outcome of CAA. Our institution long-term hearing results were poor, only $21 \%$ had a postoperative PTA of $30 \mathrm{~dB}$ HL or less. Based on our results, we recommend the centralization of CAA surgery to countries with a sufficiently large population and number of CAA patients that would guarantee the adequate experience level of the surgeon. Bone-anchored hearing devices and middle ear implants should be considered as a first-line hearing rehabilitation mode in CAA in areas without an experienced atresia surgeon, and they should be actively offered to those with suboptimal hearing postoperatively.

\section{References:}

1. De la Cruz A, Linthicum FH Jr and Luxford WM, Congenital atresia of the external auditory canal, Laryngoscope 1985;95(4):421-7

2. Kountakis SE, Helidonis E and Jahrsdoerfer RA, Microtia grade as an indicator of middle ear development in aural atresia, Arch Otolaryngol Head Neck Surg. 1995;121(8):885-6

3. Suutarla S, Rautio J, Ritvanen A et al. Microtia in Finland: Comparison of Charasteristics in Different Populations, Int J Pediatr Otorhinolaryngol 2007;71(8):1211-7

4. Jahrsdoerfer RA, Congenital Atresia of the Ear, Laryngoscope 1978;88:S1-48 
5. De La Cruz A and Teufert KB: Congenital Aural Atresia Surgery: Long-term results, Otolaryngol Head Neck Surg. 2003;129(1):121-7

6. Digoy GP and Cueva RA, Congenital Aural Atresia: Review of Short- and Long-Term Surgical Results, Otol Neurotol 2007;28(1):54-6

7. Chang SO, Choi BY and Hur DG, Analysis of the Long-Term Hearing Results After the Surgical Repair, Laryngoscope 2006;116(10):1835-41

8. Lambert PR, Congenital aural atresia: Stability of Surgical Results, Laryngoscope 1998;118(12):1801-5

9. Altmann F. Congenital atresia of the ear in man and animals. Ann. Otol. Rhinol. Laryngol.1955, 64:824-858.

10. Robinson K, Gatehouse S, Browning GG. Measuring patient benefit from otorhinolaryngological surgery and therapy. Ann Otol Rhinol Laryngol 1996;105:415-22.

11. Nadaraja GS, Gurgel RK, Kim J, Chang KW. Hearing outcomes of atresia surgery versus osseointegrated bone conduction device in patients with congenital aural atresia: a systematic review. Otology \& Neurotology, 2013 Oct;34(8):1394-9.

12. Edfeldt L, Strömbäck K. Surgical treatment of congenital aural atresia - is it still justified? Acta Otolaryngol. 2015 Mar;135(3):226-32.

13. Stalfors J, Tjellstrom A, Skin Reactions After BAHA Surgery: a Comparison Between the U-graft Technique and the BAHA Dermatome, Otol Neurotol. 2008;29(8):1109-14

14. Wazen JJ, Young DL, Farrugia MC et al. Successes and Complications of the BAHA System, Otol Neurotol. 2008;29(8):1115-9

15. Lustig LR, Arts HA, Brackmann DE et al. Hearing Rehabilitation Using the BAHA BoneAnchored Hearing Aid: Results in 40 Patients, Otol Neurotol. 2001;22(3):328-34

16. Ricci G, Volpe AD, Faralli M, Longari F, Lancione C, Varricchio AM, Frenguelli A. Boneanchored hearing aids (Baha) in congenital aural atresia: personal experience. Int J Pediatr Otorhinolaryngol. 2011 Mar;75(3):342-6.

17. Baker S, Centric A, Chennupati SK. Innovation in Abutment-free Bone-anchored Hearing Devices in Children: Updated Results and Experience. Int J Pediatr Otorhinolaryngol. 2015;79(10):1667-72

18. Rigato C, Reinfieldt S, Håkansson B et al. Audiometric Comparison Between the First Patients With the Transcutaneous Bone Conduction Implant and Matched Percutaneous Bone Anchored Hearing Device Users. Otol Neurotol. 2016;37(9):1381-7

19. Zernotti ME, Di Gregorio MF, Galeazzi $P$ et al. Comparative outcomes of active and passive hearing devices by transcutaneous bone conduction. Acta Otolaryngol. 2016;136(6):556-8

\section{Legend to the Figure}

Figure 1: Glasgow Benefit Inventory (GBI) total scores in congenital aural atresia patients. The total score is ranging from -100 (maximal negative benefit), through 0 (no benefit), to +100 (maximal positive benefit). Number 1 represents stenotic ear canal, number 2 partial atresia and number 3 total atresia.

Table 1. Postoperative results.

\begin{tabular}{lccc}
\hline & $\begin{array}{c}\text { Stenosis } \\
\mathrm{n}=3\end{array}$ & $\begin{array}{c}\text { Partial atresia } \\
\mathrm{n}=4\end{array}$ & $\begin{array}{c}\text { Total atresia } \\
\mathrm{n}=8\end{array}$ \\
\hline Male & 2 & 2 & 6
\end{tabular}


Female

Mean age, years (range)

Follow-up time, years (range)

Microtia

Mean preoperative PTA, dB HL Mean short-term PTA, dB HL Mean long-term PTA, dB HL

Diameter of auditory canal, $\mathrm{mm}$

Postoperative hospital admissions

First year*

Total**

Total GBI score

Revision surgery
25 (15-43)

$9(4-12)$

2

56

49

45

7.3
2

$19(10-34)$

$14(12-17)$

1

57

36

48

5.5
2

$22(8-53)$

$12(8-17)$

7

65

32

54

6.0

* Data not available in one patient

**Data not available in two patients

PTA: Pure tone average; GBI: Glasgow Benefit Inventory 